\title{
Fabrication of fine grain structures in Al matrices at elevated temperature by the stimulation of dual-size particles
}

\author{
Jun Liu ${ }^{\text {a }}$, Qing Zhang ${ }^{\text {a }}$, Zhe Chen ${ }^{\text {a, }}$, Lei Wang ${ }^{\text {a }}$, Gang Ji ${ }^{\mathrm{b}}$, Qiwei Shi ${ }^{\mathrm{c}, *}$, Yi Wu ${ }^{\mathrm{c}}$, \\ Fengguo Zhang ${ }^{\mathrm{c}}$, Haowei Wang ${ }^{\mathrm{a}}$ \\ ${ }^{a}$ State Key Laboratory of Metal Matrix Composites, Shanghai Jiao Tong University, Shanghai, 200240, PR China \\ ${ }^{\mathrm{b}}$ University of Lille, CNRS, INRAE, Centrale Lille, UMR 8207 - UMET - Unité Matériaux et Transformations, F-59000 Lille, France \\ ${ }^{\mathrm{c}}$ School of Materials Science and Engineering, Shanghai Jiao Tong University, Shanghai, 200240, PR China
}

\section{A R T I C L E INFO}

\section{Keywords:}

Aluminum alloys

Plasticity methods

Grains and interfaces

Dynamic recrystallization

Grain growth

Particle

\begin{abstract}
A B S T R A C T
Fabrication of fine grain structures in Al alloys at elevated temperature is of great difficulty, owing to the dramatic recrystallization and grain growth. In this study, particles with both (sub)micron and nano-scaled sizes are introduced in $\mathrm{Al}$ matrices (composites) to deeply refine and stabilize the grain structures at high temperature. Microstructural evolutions of the composites during deformation and annealing are characterized in details compared to the alloy counterparts without particles. Consequently, more rapid and obvious grain refinement are induced in the composites. Mechanisms of these grain refinement are discussed in terms of the influences of dual-size particles. Initial particle clusters can enforce grain fragmentations during unidirectional extrusion, and the subsequently dispersed micron particles accelerate the grain subdivision during orthogonal extrusion. Meanwhile, massive (sub)micron particles and dense nanoparticles promote dynamic recrystallizations in composites during deformation, thanks to the particle stimulated nucleation and lattice rotation. According to the driving and dragging forces calculation and textural results, grain growth is the major mechanism to determine the annealed structures of composites and alloys. As a result, uniformly fine grain structures are achieved in composites, approaching a stable critical size decided by the Zener pinning of nanoparticles.
\end{abstract}

\section{Introduction}

Fine grain structures are beneficial for the mechanical performances of metals, and can be fabricated by plastic deformation processing depending on the Zener-Hollomon parameters (defined as $Z=$ $\dot{\varepsilon} \exp (Q / R T)$, where $\mathrm{T}$ is the deformation temperature and $\dot{\varepsilon}$ is the strain rate) $[1-3]$. Smaller grain sizes usually result from the higher $\mathrm{Z}$ parameters. Consequently, low temperature deformations at ambient or cryogenic conditions have been adopted to produce nanocrystals or ultrafine structures $[4,5]$. Besides, ultrahigh strains are generally needed for generating small grain size as predicted by $\mathrm{Z}$ parameters, so that a variety of severe plastic deformation (SPD), such as equal channel angular pressing (ECAP), high pressure torsion (HPT) and multidirectional forging (MDF), have been applied to refine the grain structures of alloys in the past decades [6,7]. For example, Huang [8] obtained a lamellar nanograined structures $(\sim 70 \mathrm{~nm})$ in $\mathrm{Al}-4 \mathrm{wt} . \% \mathrm{Cu}$ alloys at room temperature by ECAP to a strain of 10 (15 passes).
But low-temperature deformation are difficult, if not impossible, for the high-strength alloys containing large contents of precipitates and rigid particles, so that hot deformation processing has been generally adopted. For instance, T. Sakai [9] refined 7475Al alloys at $490{ }^{\circ} \mathrm{C}$ by MDF and an average grain size of $9 \mu \mathrm{m}$ was achieved $(\epsilon \sim 6)$. I. Mazurina [10] produced fine grained structures $(\sim 6 \mu \mathrm{m})$ in $2219 \mathrm{Al}$ at $400{ }^{\circ} \mathrm{C}$ by ECAP $(\epsilon \sim 8)$. Although these SPDs have been repeated to an ultrahigh strain level, the grain structures obtained at elevated temperature $\left(>400{ }^{\circ} \mathrm{C}\right.$ ) are still larger than $5 \mu \mathrm{m}[11,12]$. In addition, these severely deformed materials are commonly followed by annealing at medium to high temperature, to release the internal stresses [13], tailor the grain structures [14] or control the precipitates $[15,16]$. Hence the asachieved fine grain structures have to resist the grain growth at high temperature, which is rarely available in most of the severely deformed alloys $[17,18]$.

As a result, different particles have been introduced in alloys to promote the grain refinement during high-temperature processing [19].

\footnotetext{
* Corresponding author.

** Corresponding author.

E-mail addresses: zhe.chen@sjtu.edu.cn, jeffchan_423@hotmail.com (Z.Chen), qwshi@sjtu.edu.cn (Q. Shi).
} 
Apps [20] found that coarse second-phase particles could accelerate the grain refinement thanks to the formation of severe deformation zones in nearby regions, which was also reported in alloys containing $\mathrm{Al}_{13} \mathrm{Fe}_{4}$ [21], $\mathrm{Si}$ [22] coarse particles. Besides, fine particles such as $\mathrm{Al}_{6} \mathrm{Mn}$ [23], $\mathrm{Al}_{2} \mathrm{O}_{3}$ [24], $\mathrm{B}_{4} \mathrm{C}$ [25] and $\mathrm{TiB}_{2} / \mathrm{TiC}$ [26] were found to enhance the interactions between particles and dislocations, promoting the grain refinements during deformation as well. However, there are also some reports illustrating that fine dispersions $\left(\mathrm{Al}_{3} \mathrm{Sc}\right)$ inhibit the formation of cells with dislocation walls, delaying the grain refinement even at high strains [27]. It indicates that the influences of particles on grain evolutions are ambiguous. Actually, the majority of literatures only focus on the effects of either micron particles or nanoparticles, which are still insufficient to induce fine grains $(<5 \mu \mathrm{m})$ individually under high temperature $\left(>400^{\circ} \mathrm{C}\right)$ and low strains $(<6)$ as summarized in Fig. $4(\mathrm{c})$. Therefore, combining micron and nano-scaled particles together to further refine the grain structures of metals at elevated temperature is necessary. The concurrent acting mechanisms of dual-size particles are of great importance as well and deserve to be studied in details. Fortunately, the composites fabricated by in-situ melt reaction consist of micron particles and nanoparticles simultaneously [28,29], providing model materials for the study of dual-size particle influences on grain refinement.

The purposes of this study are (i) to fabricate fine grain structures at high temperature, and (ii) to characterize the structural evolutions of $\mathrm{Al}$ matrices containing dual-size particles during severe plastic deformation and subsequent annealing. As a result, uniformly fine grain structures $(\sim 2 \mu \mathrm{m})$ have been introduced in $\mathrm{Al}$ matrices at $450{ }^{\circ} \mathrm{C}$, which are extremely stable even under the long-time exposure at $475{ }^{\circ} \mathrm{C}$. The last but not the least, (iii) to demonstrate the grain refinement mechanisms stimulated by dual-size particles, compared to the Al alloys.

\section{Materials and procedures}

The $7050 \mathrm{Al}$ alloys containing $8 \mathrm{wt} \% \mathrm{TiB}_{2}$ dual-size particles (referred to the composites thereafter) were initially fabricated by insitu mixed salt method [30,31] and then severely deformed by the accumulative orthogonal extrusion process (AOEP) at $450{ }^{\circ} \mathrm{C}$, which includes two steps of unidirectional extrusion $(\varepsilon \approx 2.2)$ and the subsequently orthogonal extrusion $(\varepsilon \approx 5.2)$, as described in our former study [32]. "ED 1" and "ED 2" denotes the unidirectional extrusion direction and the orthogonal extrusion direction respectively, which are vertical with each other. The as-deformed composites were subsequently annealed at $475{ }^{\circ} \mathrm{C}$ for $1 \mathrm{~h}$. Besides, $7050 \mathrm{Al}$ alloys without ceramic particles (referred to the alloys thereafter) were also manufactured as counterparts to outstand the influences of dual-size particles.

Microstructures of materials were characterized using a TESCAN MAIA3 scanning electron microscope (SEM) and a FEI Tecnai G2 transmission electron microscope (TEM). Grain structures of materials were characterized by electron backscattered diffraction (EBSD) using a TSL orientation imaging microscope system mounted on TESCAN MAIA3 SEM. The samples for EBSD analysis were prepared by mechanical polishing and additional ion-beam polishing to obtain a strainfree surface. A step size of $0.69 \mu \mathrm{m}$ and $0.13 \mu \mathrm{m}$ was used in the EBSD measurements of alloys and composites respectively. EBSD Kikuchi patterns were post-treated using CHANNEL 5.0 software package to obtain information on grain structure parameters. A misorientation criterion $\left(\geq 15^{\circ}\right)$ was used to identify high angle grain boundaries (HAGBs), and the boundaries with misorientation angles $\left(2^{\circ} \sim 15^{\circ}\right)$ were defined as low angle grain boundaries (LAGBs), while the very small misorientation angles $\left(<2^{\circ}\right)$ were ignored. All these SEM/EBSD analyses of extruded materials were performed on the normal planes along the extrusion direction (ED 1/ED 2).

\section{Results}

\subsection{Particle characteristics}

Fig. 1 are SEM micrographs of composites, showing the $\mathrm{TiB}_{2}$ particle distribution during AOEP. The in-situ synthesized $\mathrm{TiB}_{2}$ particles are dual-size distribution with both micron (0.5-2.0 $\mu \mathrm{m}$, Fig. 1(d)) and nano-scaled particles $(20-500 \mathrm{~nm}$, Fig. 1(e)), and the majority of nano$\mathrm{TiB}_{2}$ particles display well coherent orientations with Al matrices, as characterized in our former studies [33,34]. Initially, large amounts of in-situ $\mathrm{TiB}_{2}$ particles are clustered on the casting grain boundaries, as shown in Fig. 1(a). After the unidirectional extrusion, initial $\mathrm{TiB}_{2}$ particle clusters are elongated and transfer to particle bands parallel to ED 1 (Fig. 1(b)). And then these particle bands are well broken up during orthogonal extrusion, as demonstrated in Fig. 1(c). Fig. 1(d) and (e) shows the enlarged details of micron and nano-scaled $\mathrm{TiB}_{2}$ particles in AOEPed composites, which proves that AOEP can effectively disperse the in-situ $\mathrm{TiB}_{2}$ particles [28].

\subsection{Deformed structures}

\subsubsection{After unidirectional extrusion}

The grain structures of composites and alloys after unidirectional extrusion are shown in Fig. 2(a) and (d). Initial coarse grains are elongated along ED 1 and turn into columnar grains, the same as other hot extruded alloys [35]. Fig. 2(b) and (c) depict the point-to-point (d $\theta$ ) and point-to-origin $(\Delta \theta)$ misorientation within columnar grains of composites along the longitudinal (Line $T_{1}$ ) and transverse (Line $T_{2}$ ) direction respectively. The $\mathrm{d} \theta$ of composites changes abruptly and the accumulative misorientation $(\Delta \theta)$ gradient is up to $2.5^{\circ} / \mu \mathrm{m}$, indicating the presence of highly misoriented (above $6^{\circ}$ ) fragments in the columnar
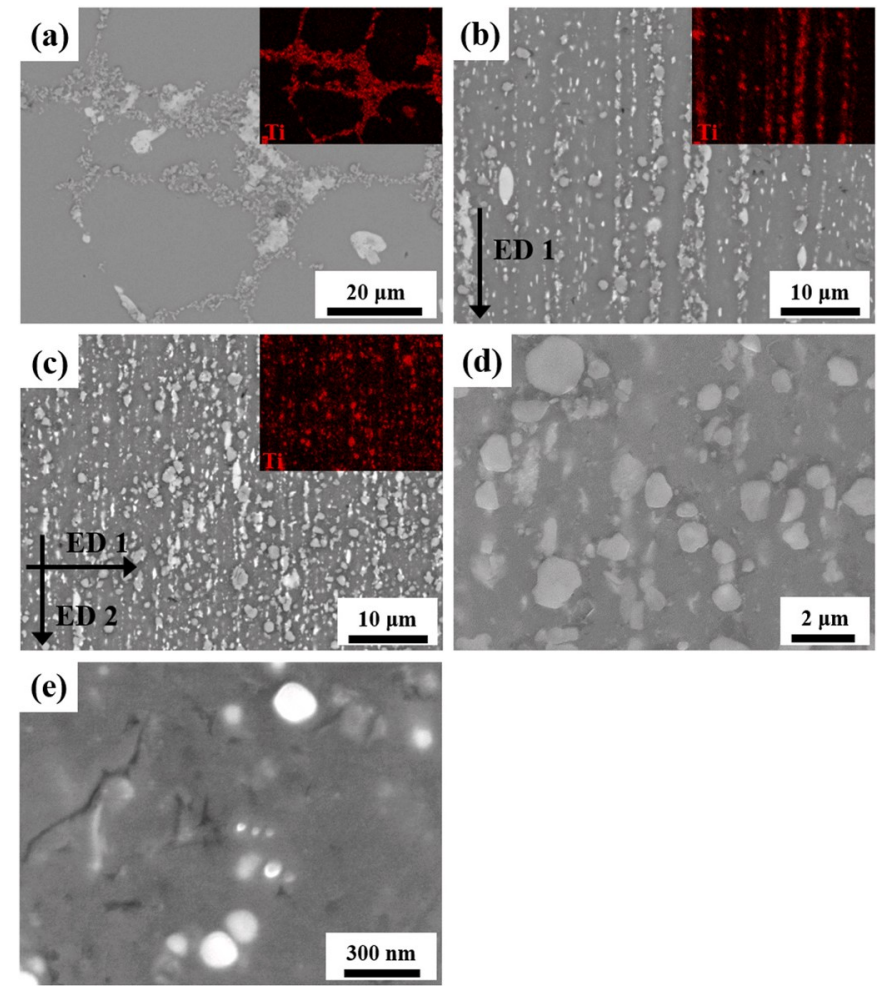

Fig. 1. SEM micrographs of composites during AOEP: (a) as-cast state, (b) after unidirectional extrusion; (c) after orthogonal extrusion. The insets are the corresponding EDX maps of Ti element in (a), (b), (c) correspondingly. (d) and (e) are the high-magnification images of (c), giving the enlarged details of micron and nano-scaled $\mathrm{TiB}_{2}$ particles in composites. The arrows indicate the individual ED. 

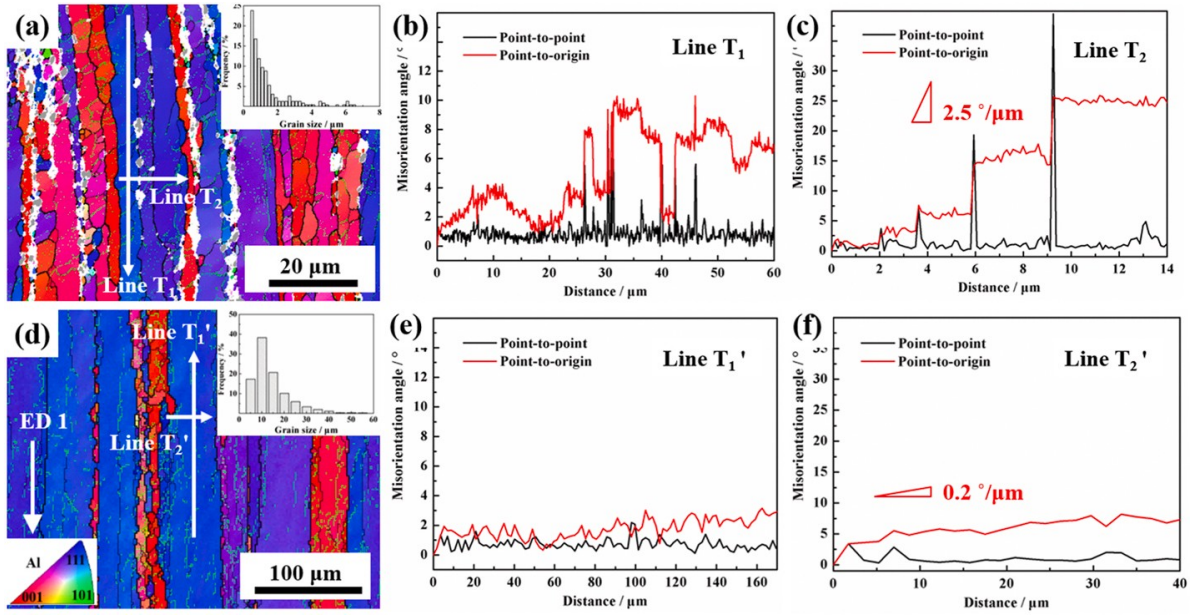

Fig. 2. EBSD maps of composites and alloys after unidirectional extrusion: the grain structures of (a) composites and (d) alloys. The insets give the corresponding grain size distribution, respectively. The point-to-point $(\Delta \theta)$ and point-to-origin $(\Sigma \Delta \theta)$ misorientation along lines: (b) Line $T_{1}$, (c) Line $T_{2}$, (e) Line $\mathrm{T}_{1}$ ', (f) Line $\mathrm{T}_{2}$ '. The HAGBs $\left(>15^{\circ}\right)$ are marked in thick black lines, the LAGBs $\left(5-15^{\circ}\right)$ are marked in thin black lines and the very low LAGBs $\left(2-5^{\circ}\right)$ are marked in thin green lines. The EBSD maps are given by IPF images whose color codes representing the crystal orientation are shown in the inset of (d), and the arrow indicates the ED. The transverse accumulative misorientation gradients of composites and alloys are given by labels. (For better interpretation of the references to color in this figure legend, the reader is referred to the $\mathrm{Web}$ version of this article.) grains. In contrast, Fig. 2(e) and (f) give the corresponding misorientation distribution of $\mathrm{Al}$ alloys in both longitudinal (Line $\mathrm{T}_{1}{ }^{\prime}$ ) and transverse (Line $\left.\mathrm{T}_{2}{ }^{\prime}\right)$ directions. The $\Delta \theta$ in $\mathrm{Al}$ alloys changes smoothly $\left(<2^{\circ}\right)$, and the accumulative misorientation $(\Delta \theta)$ gradient is consequently below $0.2^{\circ} / \mu \mathrm{m}$, which is only a tenth of that in composites.

\subsubsection{After orthogonal extrusion}

Fig. 3(a-d) illustrate the grain structures of composites and alloys after orthogonal extrusion. Former columnar grains (Fig. 2) are sectioned by new HAGBs and equiaxed grains. The as-achieved grain structures can be classified into three types of grains according to their individual aspect ratio (AR) value: (1) long fibrous grains (LFGs, $5<\mathrm{AR}$ ) parallel to ED with interior low LAGBs $\left(<5^{\circ}\right)$, (2) short ribbon grains (SRGs, $2<\mathrm{AR}<5$ ) with waved HAGBs, (3) equiaxed grains (EGs, $1<\mathrm{AR}$ $<2$ ) randomly embedded between LFGs and SRGs. Fig. 3(e) shows the frequency of grains with $\mathrm{AR}$ values in both composites and $\mathrm{Al}$ alloys after orthogonal extrusion. Low AR grains $(<3)$ are more dominant in composite structures than in alloy structures, indicating severer grain subdivision and dynamic recrystallizations (DRX) in the composites. Besides, Fig. 3(b) and (d) show that the as-achieved Al structures present long-range heterogeneities, including residual LFGs (Grain B) and abnormally growing EGs (Grain A), which will further affect the annealed homogeneity of grain structures (Fig. 5(d)).

Fig. 3(f) depicts the misorientation angle distribution in orthogonally extruded composites and alloys. The composites reveal higher misorientation angles with an average misorientation angle of $31.5^{\circ}$ and a HAGBs fraction of $63.8 \%$, compared to $23.7^{\circ}$ and $50.4 \%$ in $\mathrm{Al}$ alloys. Particularly, the inset in Fig. 3(f) shows the specific HAGBs contents of composites and alloys, illustrating that the higher HAGBs fraction in composites is owing to the increase of HAGBs larger than $45^{\circ}$. The ultrahigh HAGBs $\left(>45^{\circ}\right)$ are depicted by yellow thick lines in Fig. 3(c) and (d). It demonstrates that these ultrahigh HAGBs are identified as general SRGs and EGs boundaries in composites, but only some LFGs boundaries in $\mathrm{Al}$ alloys.

\subsubsection{Structural evolutions with strains}

The structural parameters of composites and alloys during AOEP are given in Fig. 4, varying with the accumulative strains. It can be seen in Fig. 4(a) that the composites present a higher fraction of HAGBs and larger misorientation angle than alloys, and the bigger increment $\left(\Delta \mathrm{P}_{2}\right.$ $\left.>\Delta \mathrm{P}_{1}\right)$ is obtained during the orthogonal extrusion. Fig. 4(b) demonstrates that larger grain densities are obtained in composites, indicating that more and finer SRGs and EGs are introduced during processing. And since the grain boundaries of SRGs and EGs in composites are usually above $45^{\circ}$ (Fig. 3(c)), the resultant composites exhibit more HAGBs and larger misorientation angles as shown in Fig. 3(f) and Fig. 4(a).
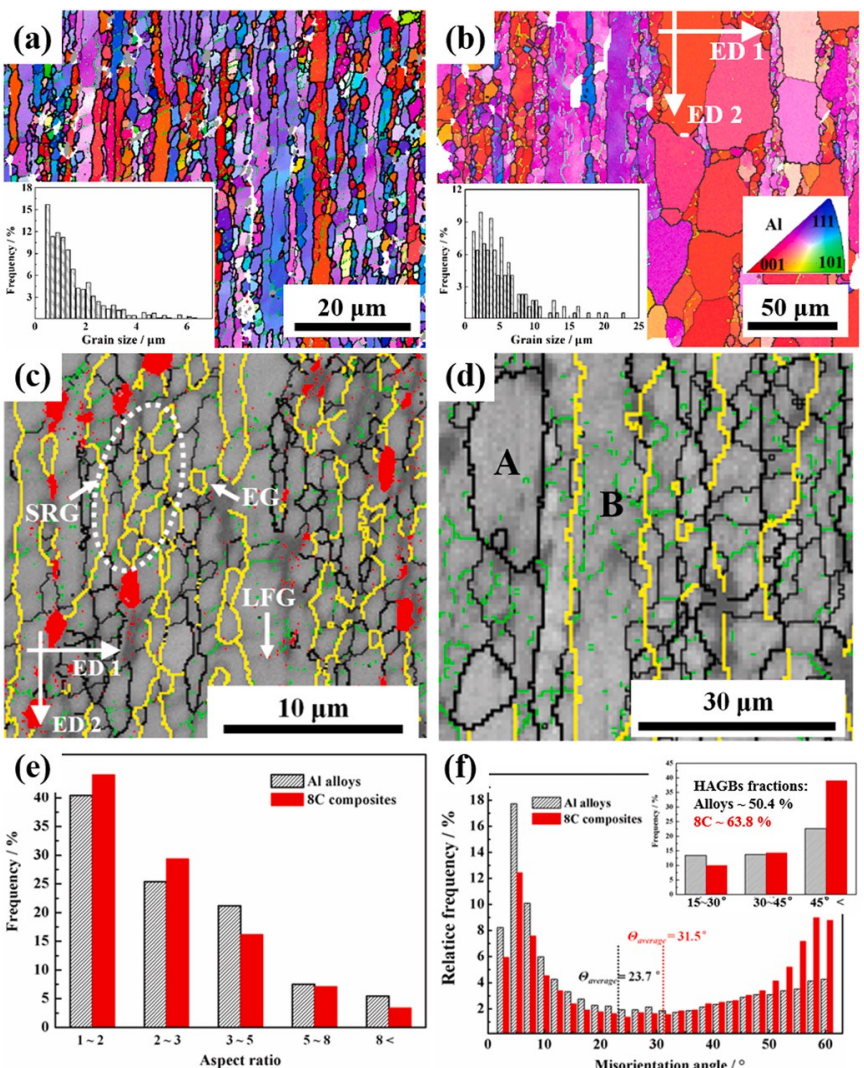

Fig. 3. EBSD maps of (a) (c)composites and (b) (d)alloys after orthogonal extrusion. The EBSD maps are given by IPF images whose color codes representing the crystal orientation are shown in the inset of (b). The insets of (a) and (b) give the corresponding grain size distribution, respectively. The ultrahigh HAGBs $\left(>45^{\circ}\right)$ are marked in thick yellow lines, the HAGBs $\left(15-45^{\circ}\right)$ are marked in thick black lines, the LAGBs $\left(5-15^{\circ}\right)$ are marked in thin black lines and the very low LAGBs $\left(2-5^{\circ}\right)$ are marked in thin green lines, correspondingly. The red phases are $\mathrm{TiB}_{2}$ particles in composites. The arrows indicate the individual ED. (e) the frequency of grains with different AR value in AOEPed materials. (f) the misorientation angle distribution of AOEPed materials, whose specific fractions of HAGBs are given in the inset. The average misorientation angle and HAGBs fraction are given by labels. (For better interpretation of the references to color in this figure legend, the reader is referred to the Web version of this article.) 

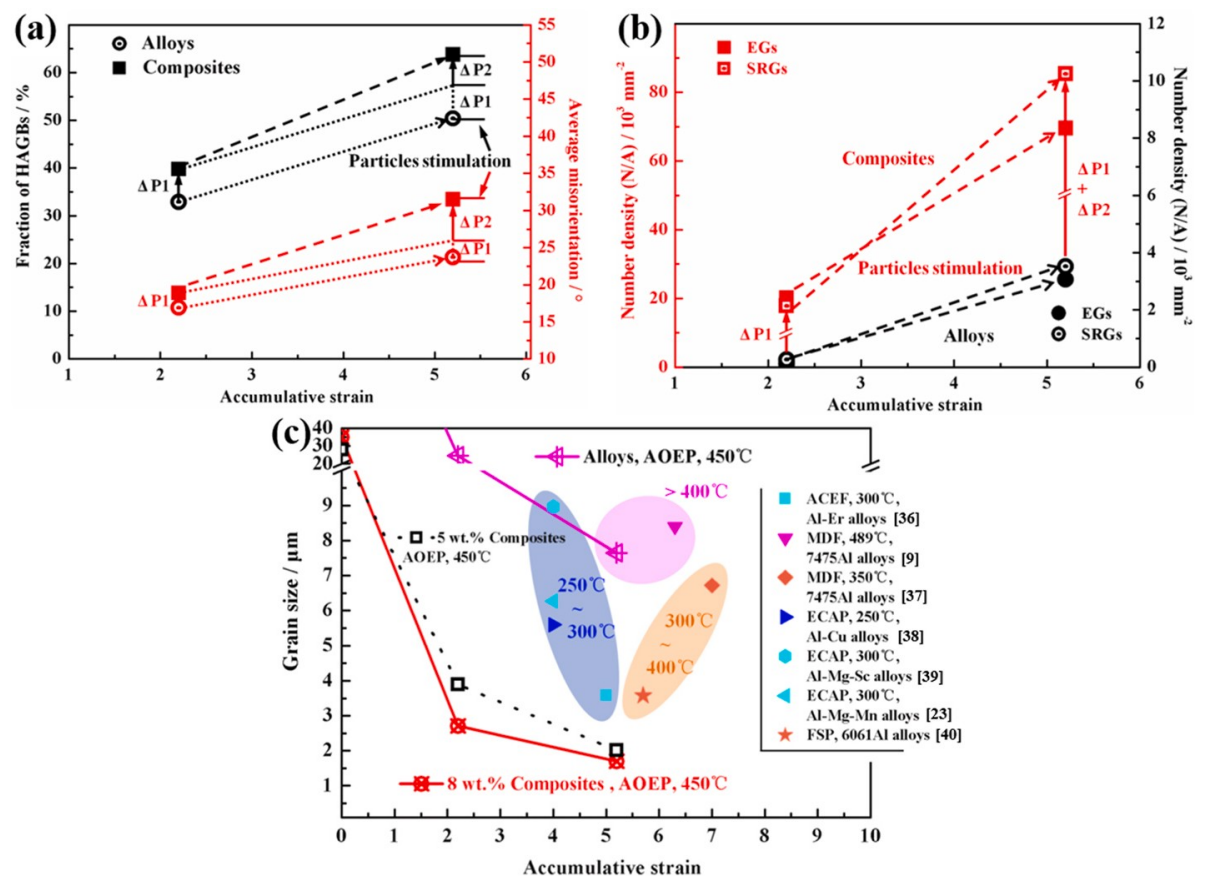

Fig. 4. Structural parameters of composites and alloys varying with accumulative strains: (a) the fraction of HAGBs and average misorientation angle, (b) grain number densities, (c) grain sizes of AOEPed materials in this study and other hot SPDed Al alloys in literatures.
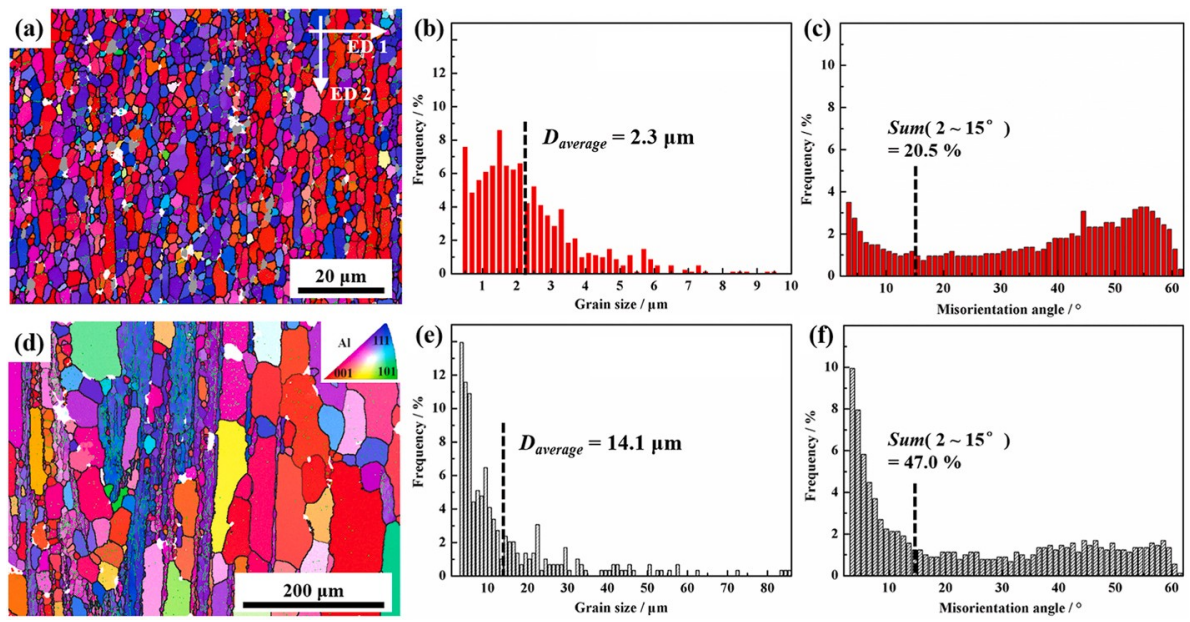

Fig. 5. EBSD maps of annealed materials: (a) composites, (d) Al alloys. The HAGBs $\left(>15^{\circ}\right)$ are marked in thick black lines, the LAGBs $\left(5-15^{\circ}\right)$ are marked in thin black lines and the very low LAGBs $\left(2-5^{\circ}\right)$ are marked in thin green lines. The structures are given by IPF images whose color codes representing the crystal orientation are shown in the inset of (d), and the arrows indicate the individual ED. Grain size and misorientation angle distribution of annealed (b) (c) composites and (e) (f) Al alloys, respectively. The labels give the average grain size and fraction of LAGBs in materials. (For better interpretation of the references to color in this figure legend, the reader is referred to the Web version of this article.)

Fig. 4(c) shows the grain size of composites and alloys in function of strains. The initial grain size $(\sim 35 \mu \mathrm{m})$ of composites dramatically decreases to $3 \mu \mathrm{m}$ after unidirectional extrusion and is further reduced to $1.7 \mu \mathrm{m}$ after the orthogonal extrusion, in comparison with a grain size above $7 \mu \mathrm{m}$ in Al alloys undergoing the identical conditions. Fig. 4(c) also compares the grain sizes of AOEPed composites and alloys with the literature data of $\mathrm{Al}$ alloys processed by other hot SPD technologies [9, $23,36-40]$. It demonstrates that fine grain structures $(3-5 \mu \mathrm{m})$ of $\mathrm{Al}$ alloys could be achieved only if either the applied strains are above 6 or the deformation temperature is below $300{ }^{\circ} \mathrm{C}$. Once the deformation temperature is beyond $400{ }^{\circ} \mathrm{C}$, coarser grain structures $(>7 \mu \mathrm{m})$ will be induced in $\mathrm{Al}$ alloys. Interestingly, although the composites are deformed at ultrahigh temperature $\left(450{ }^{\circ} \mathrm{C}\right)$ in this study, much finer structures $(<3 \mu \mathrm{m})$ are still achieved even under low strain levels $(\sim 5)$. The grain size evolution of composites with $5 \mathrm{wt} \% \mathrm{TiB}_{2}$ is also given in Fig. 4(c). Though containing a larger initial grain size, finer grain structures are obtained in the $8 \mathrm{wt} \% \mathrm{TiB}_{2}$ particles reinforced composites than those of $5 \mathrm{wt} \% \mathrm{TiB}_{2} / \mathrm{Al}$ composites. It proves that final grain sizes after large strains are not decided by the initial grain structures of materials as reported in other literatures [20,41], so that the dramatic grain refinement of composites during AOEP could be substantially attributed to the $\mathrm{TiB}_{2}$ particles.

\subsection{Annealed structures}

Grain structures of annealed composites and alloys are shown in Fig. 5. The annealed composites mainly consist of homogenous EGs with clean HAGBs (Fig. 5(a)), presenting an ultrahigh fraction $(80 \%)$ of HAGBs (Fig. 5(c)), consistent with the general characteristics of recrystallization and uniform grain growth $[12,19]$. The composites still keep a fine grain size of $2.3 \mu \mathrm{m}$ (Fig. 5(b)), even under the long-time exposure at $475{ }^{\circ} \mathrm{C}$. In contrast, the alloys undergoing identical annealing treatment reveal different features as follows: (i) the grain structures in alloys are completely heterogeneous (Fig. 5(d)), consisting of abnormal growth regions (grain size up to $200 \mu \mathrm{m}$ ), partial recrystallization zones (fine EGs) and stubborn LFGs containing dense LAGBs 
$\left(2-5^{\circ}\right)$. (ii) the grain structures of annealed alloys are much coarse with an average grain size of $14.1 \mu \mathrm{m}$ (Fig. 5(e)). (iii) the annealed alloys still retain a large fraction of LAGBs ( 47\%) (Fig. 5(f)).

\section{Discussion}

As shown above, more rapid and obvious grain refinement are achieved in composites containing dual-size $\mathrm{TiB}_{2}$ particles, in comparison with the Al alloys undergoing identical deformation and annealing processes. Specifically, (i) more HAGBs and (ii) EGs are induced during deformation, and (iii) uniformly finer structures are obtained after annealing. Mechanisms of these grain refinement will be discussed in terms of the dual-size $\mathrm{TiB}_{2}$ particles in this section.

\subsection{Dynamic grain refinement during deformation}

\subsubsection{Particles accelerate grain subdivision}

(1) Grain fragmentation during unidirectional extrusion

Fig. 6(a) and (c) shows the internal fine structures of columnar grains in composites and alloys, respectively. Textural columnar grains with recovered cells $\left(\sim 2^{\circ}\right)$ are achieved in Al alloys after unidirectional extrusion as shown in Fig. 2(d) and Fig. 6(c), but the grain structures of composites are more fragmental containing highly misoriented substructures (Fig. 6(a)). Fig. 6(b) and (d) illustrates the orientation maps of substructures within columnar grains of composites and alloys. The substructures in composites exhibit scattered orientations with few domains $(3 / 4 / 5)$ rotated from the matrices $(1 / 2 / 6)$, but the orientations within the columnar grain of $\mathrm{Al}$ alloys are much clustered.

Fig. 6(e) illustrates the structural evolutions of polycrystalline alloys during deformation. When the applied shear stress rises to a critical level, slip systems with high Schmid factor will be activated firstly, resulting in deformation bands in initial grains. The moving dislocations continue to slip and stop at the intersection between deformation bands

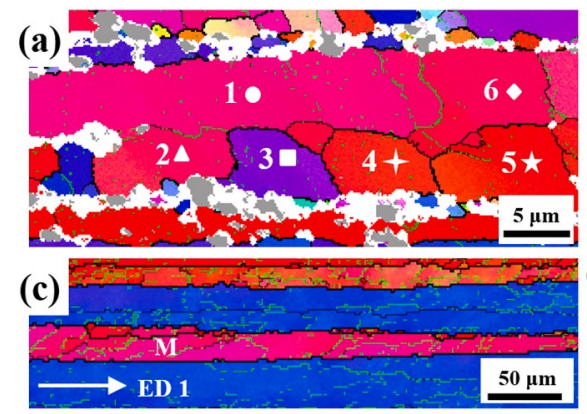

\section{(e)}
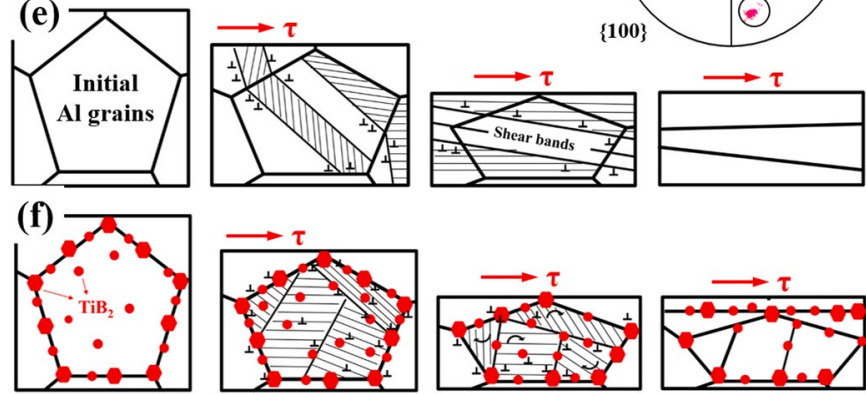

Fig. 6. Enlarged images of columnar grains in (a) composites and (c) alloys after unidirectional extrusion. (b) and (d) are the pole figures of columnar grains in (a) and (c). The corresponding substructures are numbered and given by labels. Schematic diagrams showing the grain evolution of (e) alloys and (f) composites during deformation. (For interpretation of the references to color in this figure legend, the reader is referred to the Web version of this article.) and grain boundaries, increasing the local stress high up to trigger the slip systems in neighbor grains. Once the neighboring slip systems start to move, surrounding grains will begin to deform coordinately, introducing permanent shear bands in long ranges. These shear bands keep rotating towards ED during extrusion, transforming into the elongated grain structures in Fig. 2(d) and Fig. 6(c). However, the initial composite grains are surrounded by dense $\mathrm{TiB}_{2}$ particle clusters (Fig. 1(a)), which will hinder the transfer of slip bands between neighbor grains and prevent the formation of long-range shear bands, as shown in Fig. 6(f) schematically. These isolated grains tend to deform alone and then more active slip systems are needed to keep the plastic deformation contiguity, resulting in misoriented domains inside grains. Besides, higher stress are accumulated near the grain boundaries (around particle clusters) as well, promoting the rotation of subgrains to further increase the interior misorientations. Consequently, more grain fragments are introduced in the extruded composites as shown in Fig. 2(a) and Fig. 6(a).

(2) Grain subdivision during orthogonal extrusion

Fig. 7 show the distributions of Schmid factor in unidirectionally extruded composites and alloys loading along ED 2 (vertical to ED 1). The fragmental composites have more grains with high Schmid factor $(>0.45)$, so that the dislocation slip systems in composites are easy to be activated to form deformation heterogeneities (deformation cells/ bands) during the orthogonal extrusion. More importantly, former $\mathrm{TiB}_{2}$ particle bands are well dispersed during the orthogonal extrusion (Fig. 1 (c)), leaving micron particles uniformly embedded in Al matrices (Fig. 1 (d)). As reported in literatures [20,42], the large $(>1 \mu \mathrm{m})$ non-deformable particles can promote the lattice rotation of substructures, inducing sharp misorientation gradient and HAGBs in the nearby matrices. Fig. 8 give the microstructures and line scan misorientations around micron $\mathrm{TiB}_{2}$ particles in composites. Substructures with ultrahigh HAGBs $\left(>45^{\circ}\right)$ are consequently induced in the particle deformation zones, and high misorientations are accumulated within (Line 1) and across (Line 2) the grains, resulting in the sharp misorientation gradient (up to $10 \% \mu \mathrm{m}$ ) around particles. Since these micron $\mathrm{TiB}_{2}$ particles are widely distributed in matrices (Fig. 1(c)), large amounts of highly misoriented substructures and HAGBs are introduced in composites, subdividing the coarse grains (LFGs) into finer fragments (SRGs or EGs), as shown in Fig. 3(c). These extra HAGBs discussed in this section (4.1.1) are geometrically necessary to accommodate the inhomogeneous strains among different domains, leading to the straininduced grain refinement (grain subdivision), which is different from the grain refinement caused by DRX as discussed below (4.1.2).

\subsubsection{Particles promote dynamic recrystallization}

There are highly misoriented deformation zones around micron particles (Fig. 8), providing driving energies for the nucleation of recrystallization grains, as the so called particle stimulated nucleation of recrystallizations (PSN). Numbers of micron $\mathrm{TiB}_{2}$ particles are dispersed completely during AOEP to guarantee the massive occurrences of PSN in Al matrices, so that the resultant composites present more EGs than the alloys (Fig. 3(a) and Fig. 4(b)). Fig. 9(a) shows the typical PSN occurring in composites. It is noteworthy that the widely accepted critical particle size for PSN is about $1 \mu \mathrm{m}$ below which no PSN will exist. But the recrystallized nuclei in composites are not only found surrounding micron $(>1 \mu \mathrm{m})$ particles, but also nearby the submicron ones $(<1 \mu \mathrm{m})$, as shown in Fig. 9(a).

Fig. $9(\mathrm{~b})$ is the schematic diagram of particles stimulated recrystallization, illustrating the driving $\left(F_{d}\right)$ and dragging force $\left(F_{c}+F_{r}\right)$ for PSN in composites. The driving force $\left(F_{d}\right)$ for nucleus is stem from the stored dislocations [43], as given by equation (1):

$F_{d}=\alpha G b^{2} \rho$

Where $\alpha$ is a constant of $0.5, \mathrm{G}$ is the shear modulus of $\mathrm{Al}$ at deformation 

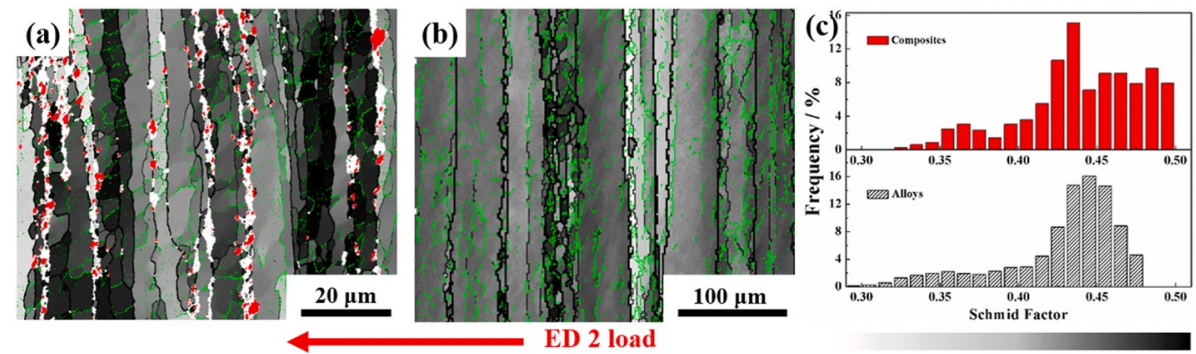

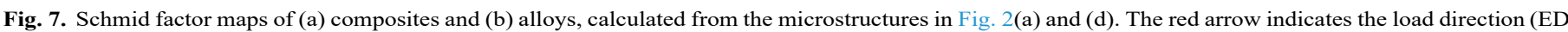

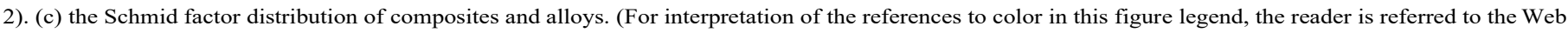
version of this article.)

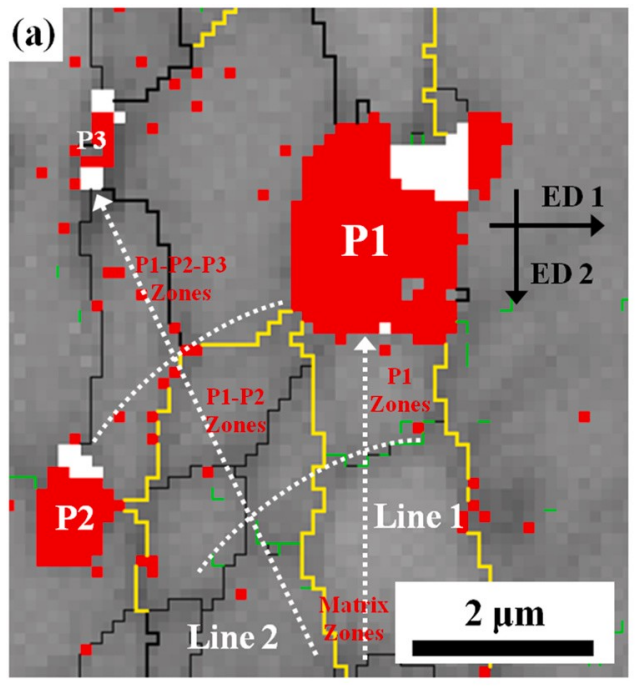

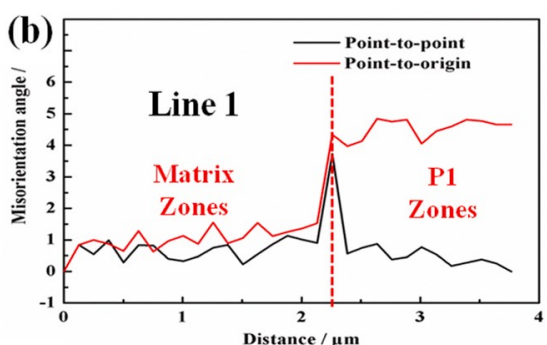

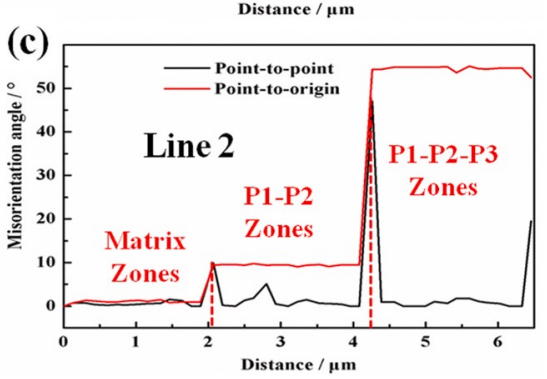

Fig. 8. (a) the high resolution EBSD map of composites after orthogonal extrusion. The ultrahigh HAGBs $\left(>45^{\circ}\right)$ are marked in thick yellow lines, the HAGBs $\left(15-45^{\circ}\right)$ are marked in thick black lines, the LAGBs $\left(5-15^{\circ}\right)$ are marked in thin black lines and the very low LAGBs $\left(2-5^{\circ}\right)$ are marked in thin green lines, respectively. The red phases are $\mathrm{TiB}_{2}$ particles and the arrows give individual ED. (b) and (c) shows the misorientation distribution along the Line 1 and Line 2 in (a). (For interpretation of the references to color in this figure legend, the reader is referred to the Web version of this article.) temperature, which is about $24 \mathrm{GPa}$ at $450{ }^{\circ} \mathrm{C}[44], \mathrm{b}=0.283 \mathrm{~nm}$ is the Burgers vector, and $\rho$ is the dislocation density within the deformation zones surrounding particles.

If the recrystallized grains are nucleated and grow into the deformed structures, extra grain boundary areas with specific energy $(\gamma)$ will be induced, so that there will be a dragging pressure $\left(F_{c}\right)$ to shrink the new nucleus [43], given by:

$F_{c}=\frac{2 \gamma}{R}$

Where $\mathrm{R}$ is the radius of new grains, $\gamma=0.32 \mathrm{~J} \mathrm{~m}^{-2}$ is the grain boundary energy of Al.

In addition, dense $\mathrm{TiB}_{2}$ nanoparticles are uniformly distributed in $\mathrm{Al}$ matrices (Fig. 1(e)), which inhibit the nucleus growth known as Zener pinning pressure, providing the extra retarding force $\left(\mathrm{F}_{\mathrm{r}}\right)$ for recrystallization, given by Ref. [45]:

$F=\frac{3 f_{\underline{\nu}} \underline{\underline{F}}}{2 r}$

Where $f_{v}$ and $r$ is the volume fraction and mean radius of nanoparticles, which is about 0.032 and $17 \mathrm{~nm}$ in this $\mathrm{TiB}_{2} / \mathrm{Al}$ composites, according to our former studies [28].

Only if the driving force $\left(\mathrm{F}_{\mathrm{d}}\right)$ is large enough to overcome the dragging forces $\left(\mathrm{F}_{\mathrm{c}}+\mathrm{F}_{\mathrm{r}}\right)$, can the PSN occur in composites, as demonstrated by the PSN criterion in Fig. 9(b). Thus, the dislocation density ( $\rho$ ) around particle is the major determining factor for recrystallization, which is related to the misorientation $(\theta)$ and distance $(\mathrm{x})$ from particle as follows [43]:

$$
\rho=\frac{2 c_{1} \tan \theta_{\max } \cos ^{2} \theta \quad \operatorname{cxp}\left(-{ }_{d} \underline{\underline{c}}\right)}{b d}
$$

And the misorientation $(\theta)$ around particle can be given empirically as [43]:

$\tan \theta=\tan \theta_{\max } \exp \left(-\frac{c_{1} x}{d}\right)$

Where $\mathrm{c}_{1}$ is a constant $(\sim 1.8), \mathrm{d}$ is the diameter of large particle. $\theta$ max is the maximum misorientation nearby each particle. For the particles between $0.1 \mu \mathrm{m}$ and $2.5 \mu \mathrm{m}, \theta_{\max }$ is a function of both strain and particle size, given by Refs. [43]:

$\theta_{\max }=0.8 \theta_{s}(d-0.1)^{0.2}$

Where $\theta_{\mathrm{s}}$ is the maximum misorientation decided by strains. In the case of composites in this study, particles undergo identical strains $(\sim 5.2)$ during deformation. And thus a linear relationship can be derived from the measured maximum misorientation $\left(\theta_{\max }\right)$ and corresponding particle parameters $((\mathrm{d}-0.1)$
about 0.859 is achieved in this , AOS shown in Fig. $9(\mathrm{c})$. A similar slope value of $\theta_{\mathrm{s}}$ about $61.5^{\circ}$.

For the analysis of PSN, a critical nucleus size is usually assumed equal to the particle diameter $(x=2 \mathrm{R}=\mathrm{d})$ to simplify the calculation [19]. Therefore, we can calculate the driving force $\left(F_{d}\right)$ and dragging forces $\left(F_{c} F_{r}\right)$ for PSN around different particles $(0.1-2.5 \mu \mathrm{m})$, as depicted in Fig. 9(d). The driving force for PSN is always larger than the dragging forces in composites, no matter what particle size is. It is the reason why some submicron $\mathrm{TiB}_{2}$ particles below the general critical size 

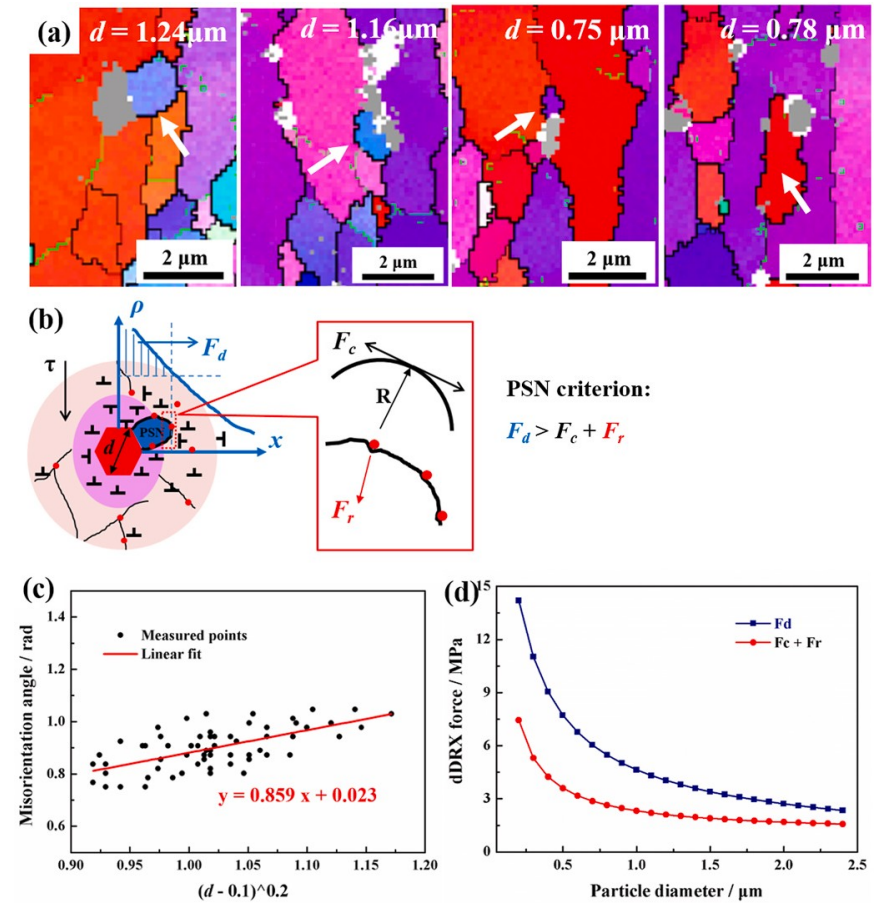

Fig. 9. (a) the high resolution EBSD maps of composites after AOEP, showing the presences of dynamic PSN around micron $(>1 \mu \mathrm{m})$ and submicron $(<1 \mu \mathrm{m})$ particles. The HAGBs $\left(>15^{\circ}\right)$ are marked in thick black lines, the LAGBs $\left(5-15^{\circ}\right)$ are marked in thin black lines and the very low LAGBs $\left(2-5^{\circ}\right)$ are marked in thin green lines, correspondingly. The gray phases are $\mathrm{TiB}_{2}$ particles. The individual particle size is given by label. The white arrows indicate the recrystallized nuclei around particles. (b) the schematic diagrams illustrating the mechanisms of PSN in composites. (c) the measured maximum misorientation angle around each particle versus particle size, and the linear fit equation is given as well. (d) the calculated driving $\left(F_{d}\right)$ and dragging forces $\left(F_{c}+F_{r}\right)$ for PSN in the function of particle diameter. (For interpretation of the references to color in this figure legend, the reader is referred to the Web version of this article.)

\section{$(\sim 1 \mu \mathrm{m})$ trigger the PSN as well (Fig. 9(a)).}

According to the calculation (equation (4)), the dislocation density $(\rho)$ around $\mathrm{TiB}_{2}$ particles during deformation has been up to the order of $10^{15} / \mathrm{m}^{2}$, so that it finally induces a very large value of misorientation $\left(\theta_{\mathrm{s}} \sim 61.5^{\circ}\right)$ nearby the particles, which is usually below $50^{\circ}$ in $\mathrm{Al}$ alloys under identical strains $(\varepsilon \sim 5)[19,43]$. Such an ultrahigh driving force can be attributed to two major factors: Firstly, the progressive lattice rotation promoted by micron $\mathrm{TiB}_{2}$ particles like other large particles in literatures. Furthermore, these submicron and micron $\mathrm{TiB}_{2}$ particles are surrounded by dense nanoparticles (Fig. 1(e)), which can effectively hinder dislocations and mitigate the dynamic recovery during hot deformation, so that considerable dislocation density is achieved in Al matrix to afford the ultrahigh driving force.

In addition, few EGs are also found far from the (sub)micron $\mathrm{TiB}_{2}$ particles in composites (Fig. 10(a)), indicating the presence of another DRX mechanism (apart from PSN) during deformation. Although the dynamic recovery is mitigated by the dense nanoparticles in composites, there are still small recovered cells near the HAGBs (subgrains A/B in Fig. 10(a)) because of the high stacking fault energy (SFE) of Al. These recovered subgrain boundaries are initially pinned by dense $\mathrm{TiB}_{2}$ nanoparticles (Fig. 1(e)), which will continue to trigger dislocations during further deformation. As a result, massive dislocations are accumulated at the recovered grain boundaries, gradually increasing the misorientation of subgrains by lattice rotation, as illustrated in Fig. 10 (b) and (c). Consequently, extra EGs with non-equilibrium HAGBs (high up to $50^{\circ}$ shown in Fig. 10(a)) are introduced in resultant composites, owing to the promotion of dense $\mathrm{TiB}_{2}$ nanoparticles. Such a similar process of lattice rotation is usually responsible for the development of
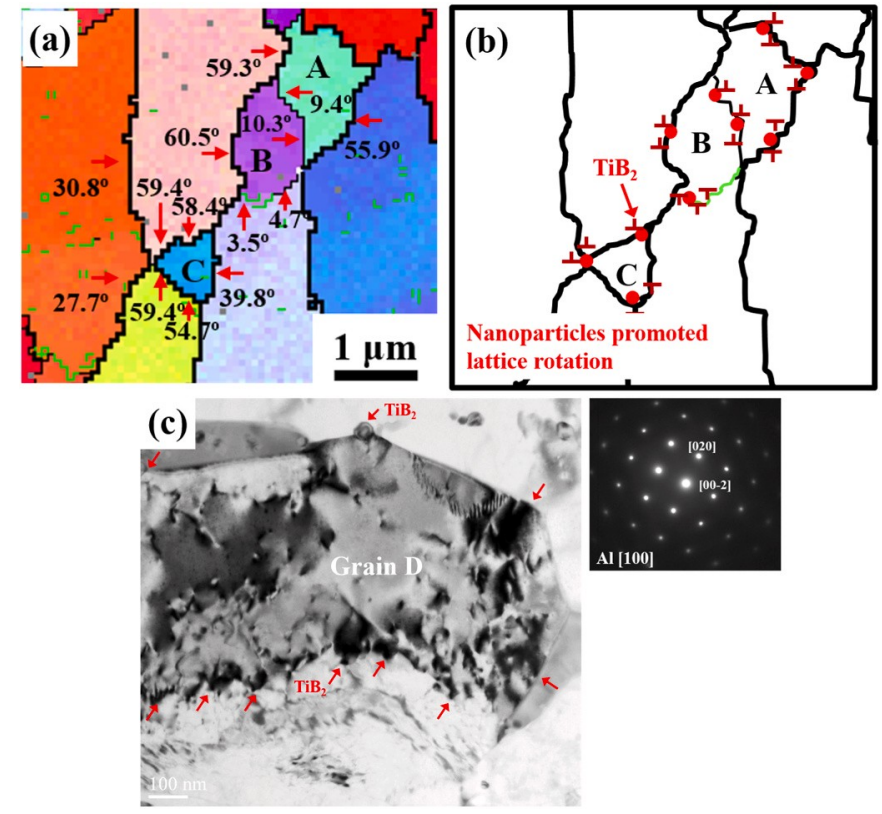

Fig. 10. (a) The high resolution EBSD maps of composites, giving the local grain boundary misorientation of subgrains (A,B) and EGs (C). (b) The schematic diagrams illustrating the mechanisms of nanoparticles promoted DRX in composites. (c) TEM images showing the interactions between dislocations and nanoparticles on (sub)grain boundaries. The inset is the diffraction patterns of Grain D. (For interpretation of the references to color in this figure legend, the reader is referred to the Web version of this article.)

fine grain structures in high SFE alloys, as the so called continuous dynamic recrystallizations during thermomechanical processes $[12,46]$. With the concurrent stimulations of both (sub)micron and nano-scaled $\mathrm{TiB}_{2}$ particles, more and finer EGs are introduced in Al matrices during deformation, dynamically refining the grain structures of composites, as shown in Fig. 3 and Fig. 4.

\subsection{Grain stabilization during annealing}

Grain structures of Al alloys are susceptible to dynamically abnormal growth during deformation (such as grain A in Fig. 3(d)), while the composite structures are very stable without ultra-large grains. Such a difference in grain stabilization is enlarged during high-temperature annealing, resulting in heterogeneously coarse grains in alloys but uniformly fine structures in composites, as shown in Fig. 5.

As discussed in 4.1.2, stable nucleus of recrystallization will be formed only if the driving force $\left(\mathrm{F}_{\mathrm{d}}\right)$ is larger than the dragging force, which is the sum of $F_{c}$ (equation (2)) and $F_{r}$ (equation (3)) in composites but only $F_{c}$ in alloys. With regard to the driving force in materials after AOEP (Fig. 3(a) and (b)), the dislocation densities (geometrically necessary dislocations, GNDs) can be calculated by the strain gradient model [47]:

$\rho_{G N D s}=\frac{2 \theta_{K A M}}{x b}$

Where $\rho_{\mathrm{GNDs}}$ is the density of GNDs, $\theta_{\mathrm{KAM}}$ is the kernel average misorientation, $x$ is the unit length (twice of the step size used in EBSD acquisition, which is $690 \mathrm{~nm}$ and $130 \mathrm{~nm}$ for $\mathrm{Al}$ alloys and composites, respectively).

Assuming that GNDs account for $90 \%$ of the total dislocations in each region $\left(\rho_{\text {total }}=\rho_{\mathrm{GNDs}} / 0.9\right)[48]$ and the maximum nucleus size is equal to the subgrain size in composites $(\sim 1.5 \mu \mathrm{m})$ and alloys $(\sim 4.4 \mu \mathrm{m})$, the critical $\theta_{\mathrm{KAM}}$ for nucleation can be derived from equations (1)-(3) and (7). Consequently, a $\theta_{\text {KAM }}$ of $3.8^{\circ}$ and $3^{\circ}$ is needed at least to ensure the nucleation of recrystallized grains in composites and alloys. Fig. 11 show 

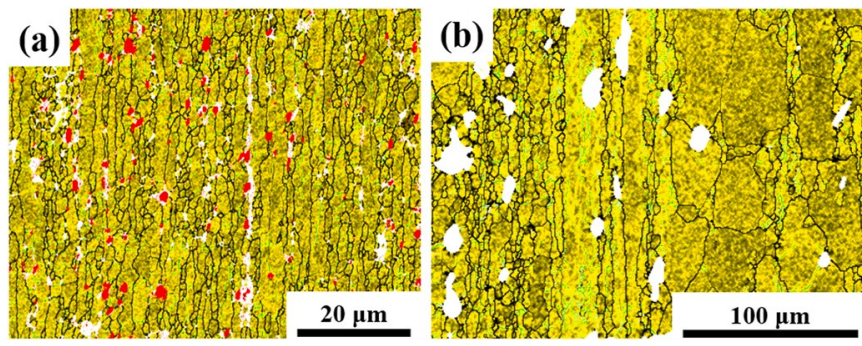

(c)
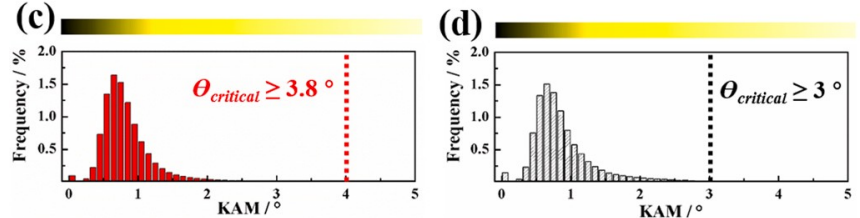

Fig. 11. The kernel average misorientation $\left(\theta_{\mathrm{KAM}}\right)$ maps and corresponding distributions of $\theta_{\text {KAM }}$ in AOEPed (a) (c) composites and (b) (d) alloys. The critical $\theta_{\text {KAM }}$ for nucleation is given by label. The red phases in (a) are $\mathrm{TiB}_{2}$ particles. (For interpretation of the references to color in this figure legend, the reader is referred to the $\mathrm{Web}$ version of this article.)

the $\theta_{\text {KAM }}$ distributions in AOEPed composites and alloys. It illustrates that majorities of $\theta_{\text {KAM }}$ in deformed materials are around $1^{\circ}$, far below the critical $\theta_{\text {KAM }}$ demanded for nucleation. That is to say, since the dramatic DRX has consumed most of the deformation capacity, the remnant energy is too low to trigger the nucleation of new grains during annealing, so that the final grain structures are mainly decided by the growth of existing nuclei or EGs, as the so called metadynamic recrystallization in literatures $[12,49]$.

Fig. 12 give the pole figures of composites and alloys before and after annealing. The AOEPed materials exhibit dominant Brass $((011)<211>)$ textures [28], and few Cube $((001)<100>)$ textures are also detected in both composites and alloys. The annealed materials keep the same textures (weaker Brass, but stronger Cube) as deformed ones, without the formation of new types of recrystallization textures, which proves that there are no newly recrystallized grains during annealing as discussed above. However, the Cube textures in either composites or alloys are strengthened after annealing as shown in Fig. 12(b) and (d). It is
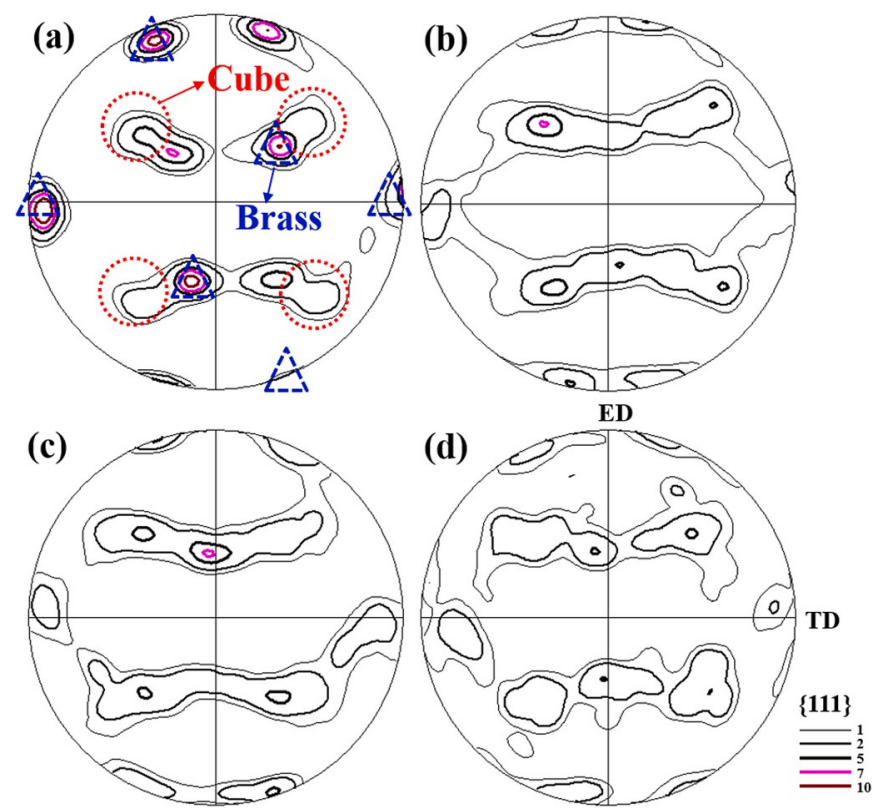

Fig. 12. Pole figures of composites: (a) AOEPed, (b) annealed. And alloys: (c) AOEPed, (d) annealed. The typical textures are indicated by labels. mainly because that Cube nuclei are easy to form owing to the mechanism of strain induced grain boundary migration at the boundaries of Cube-oriented regions in deformed microstructures, especially in the Al alloys under high-temperature deformation [50,51]. These recrystallized Cube grains continue to grow during annealing, further increasing their orientation intensities. In contrast, remnant grains with deformation textures are gradually consumed by the growth of dynamically recrystallized nuclei/grains, so that the intensities of Brass textures are decreased after annealing.

As discussed above, grain growth during annealing is of great importance to determine the final structures in both composites and alloys. Fig. 13 illustrates the grain growth mechanisms in composites, where the dragging force is the Zener pinning pressure $\left(\mathrm{F}_{\mathrm{r}}\right.$ in equation (3)) [52], but the pressure $\left(F_{c}\right.$ in equation (2)) arising from the curvature of grain boundary turns out to be the driving force for grain growth. Besides, the remnant deformation structures with recovered substructures $\left(D_{\text {sub }}\right)$ can provide parts of driving force for growth as well [43], given by:

$F_{\bar{a}} \frac{3 \gamma}{D_{s u b}}$

Where $\mathrm{D}_{\text {sub }}=1.5 \mu \mathrm{m}$ is the subgrain size in composites. On the assumption that the driving $\left(F_{c}+F_{d}\right)$ force is equal to the dragging force $\left(\mathrm{F}_{\mathrm{r}}\right)$, a stable grain size close to $4.9 \mu \mathrm{m}$ will be obtained in the annealed composites. Although the deformed composites structures are somewhat heterogeneous as shown in Fig. 3(a) and (c), fine grains will stop growing once the grain size approaching the stable size, inducing final uniform and fine grain structures in composites [52]. In contrast, there is no dragging force $\left(\mathrm{F}_{\mathrm{r}}\right)$ for the grain growth of alloys, so that the finegrained structures will keep growing even under a small driving pressure. Thus, heterogeneously coarse grains (Fig. 5(d)) are finally achieved in alloys, inheriting from the inhomogeneous structures in deformed state (Fig. 3(b) and (d)).

\section{Conclusions}

Both (sub)micron and nano-scaled particles have been introduced in Al matrices to refine the grain structures at elevated temperature, and fine grain structures are obtained in the composites. Mechanisms of grain refinement and stabilization in composites have been discussed in details based on the influences of dual-size particles. Main conclusions are as follows:

(1) In comparison with Al alloys, the composites present more rapid and obvious grain refinement under identical deformation and annealing processes, including (i) more ultrahigh HAGBs and equiaxed grains after deformation, and (ii) more uniform and finer grain structures after annealing.

(2) Particle clusters can hinder the neighboring transfer of slip bands between grains and prevent the formation of long-range shear bands, enforcing the interior grain fragmentations during unidirectional extrusion. Subsequently, dispersed micron particles increase misorientation gradient in the nearby regions, inducing grain subdivision during orthogonal extrusion.

(3) DRX have been promoted in the composites during deformation, thanks to the PSN and lattice rotation stimulated by dual-size particles.

(4) Grain growth is the major mechanism to determine the annealed structures of both composites and alloys. Uniform and fine grain structures are achieved in composites, approaching a stable critical size decided by the Zener pinning of nanoparticles.

(5) The strategies of fabricating fine grain structures at elevated temperature by the introduction of dual-size particles are both effective and achievable, which can be extended in other metalparticle systems. 

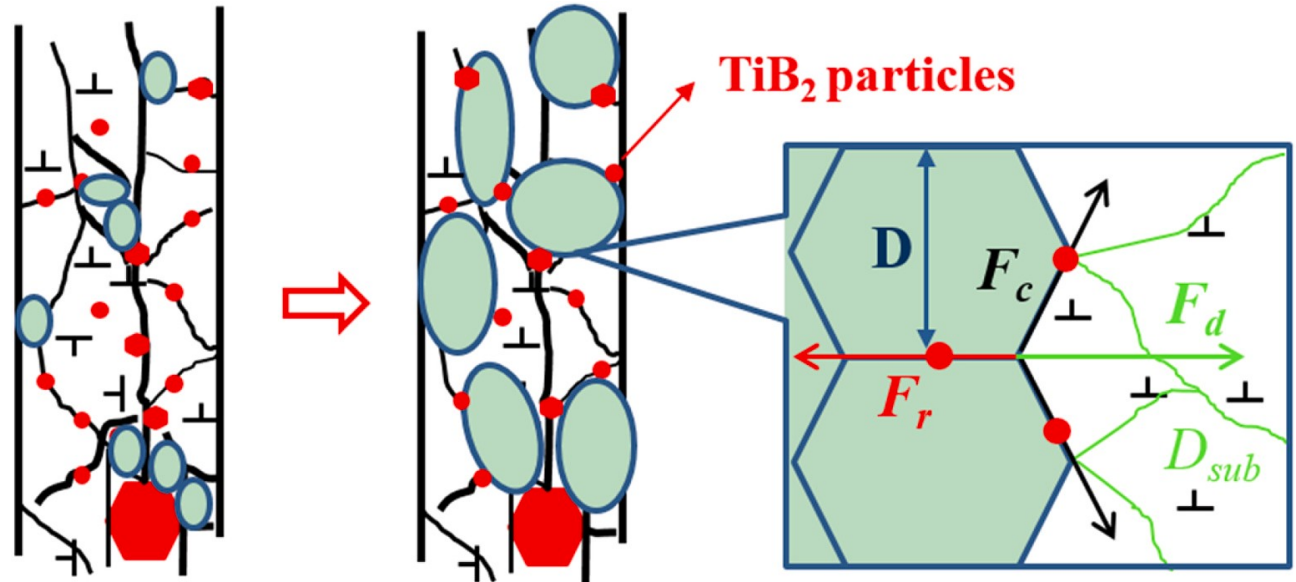

Fig. 13. The schematic diagrams showing the grain growth mechanisms with driving $\left(F_{c}+F_{d}\right)$ and dragging force $\left(F_{r}\right)$ in composites

\section{Data availability}

The raw/processed data required to reproduce these findings cannot be shared at this time as the data also forms part of an ongoing study.

\section{CRediT authorship contribution statement}

Jun Liu: Data curation, Writing - original draft, writing-original draft preparation, All authors have read and agreed to the published version of the manuscript. Qing Zhang: Methodology, Software, All authors have read and agreed to the published version of the manuscript. Zhe Chen: Writing - review \& editing, writing and editing, All authors have read and agreed to the published version of the manuscript, Funding acquisition, All authors have read and agreed to the published version of the manuscript. Lei Wang: Methodology, Software, All authors have read and agreed to the published version of the manuscript. Gang Ji: Writing - review \& editing, writing and editing, All authors have read and agreed to the published version of the manuscript. Qiwei Shi: Writing - review \& editing, writing and editing, All authors have read and agreed to the published version of the manuscript. Yi Wu: Supervision, All authors have read and agreed to the published version of the manuscript. Fengguo Zhang: Methodology, Software, All authors have read and agreed to the published version of the manuscript. Haowei Wang: Supervision, Funding acquisition, All authors have read and agreed to the published version of the manuscript.

\section{Declaration of competing interest}

None.

\section{Acknowledge}

This work is financially supported by the National Natural Science Foundation of China [Nos. 51971137, 11875192, U1930101].

\section{References}

[1] J. Zhao, Y. Deng, J. Tan, J. Zhang, Mater. Sci. Eng. 734 (2018) 120-128.

[2] A. Chamanfar, M.T. Alamoudi, N.E. Nanninga, W.Z. Misiolek, Mater. Sci. Eng. 743 (2019) 684-696.

[3] Y. Wang, J. Li, Y. Xin, C. Li, Y. Cheng, X. Chen, M. Rashad, B. Liu, Y. Liu, Mater. Sci Eng. 768 (2019) 138483

[4] S.H. Lee, Y. Saito, T. Sakai, H. Utsunomiya, Mater. Sci. Eng. 325 (2002) 228-235.

[5] A. Polkowska, S. Lech, W. Polkowski, Mater. Sci. Eng. 787 (2020) 139478.

[6] Y. Estrin, A. Vinogradov, Acta Mater. 61 (2013) 782-817.

[7] T.G. Langdon, Acta Mater. 61 (2013) 7035-7059.

[8] Y. Huang, J.D. Robson, P.B. Prangnell, Acta Mater. 58 (2010) 1643-1657.

[9] T. Sakai, H. Miura, A. Goloborodko, O. Sitdikov, Acta Mater. 57 (2009) 153-162.
I. Mazurina, T. Sakai, H. Miura, O. Sitdikov, R. Kaibyshev, Mater. Sci. Eng. 486 (2008) 662-671.

[11] R.Z. Valiev, T.G. Langdon, Prog. Mater. Sci. 51 (2006) 881-981.

[12] T. Sakai, A. Belyakov, R. Kaibyshev, H. Miura, J.J. Jonas, Prog. Mater. Sci. 60 (2014) 130-207.

[13] R.K. Islamgaliev, N.F. Yunusova, I.N. Sabirov, A.V. Sergueeva, R.Z. Valiev, Mater. Sci. Eng. 319-321 (2001) 877-881.

[14] G.H. Zahid, Y. Huang, P.B. Prangnell, Acta Mater. 57 (2009) 3509-3521.

[15] K. Huang, K. Zhang, K. Marthinsen, R.E. Logé, Acta Mater. 141 (2017) 360-373.

[16] A. Deschamps, F. De Geuser, Z. Horita, S. Lee, G. Renou, Acta Mater. 66 (2014) $105-117$.

[17] M. Sarkari Khorrami, N. Saito, Y. Miyashita, Mater. Char. 151 (2019) 378-389.

[18] J. Duan, H. Wen, C. Zhou, X. He, R. Islamgaliev, R. Valiev, Mater. Char. 159 (2020) 110004.

[19] K. Huang, K. Marthinsen, Q. Zhao, R.E. Logé, Prog. Mater. Sci. 92 (2018) 284-359.

[20] P.J. Apps, J.R. Bowen, P.B. Prangnell, Acta Mater. 51 (2003) 2811-2822.

[21] M. Berta, P.J. Apps, P.B. Prangnell, Mater. Sci. Eng. 410-411 (2005) 381-385.

[22] I. Gutierrez-Urrutia, M.A. Muñoz-Morris, D.G. Morris, Acta Mater. 55 (2007) $1319-1330$.

[23] I. Nikulin, A. Kipelova, S. Malopheyev, R. Kaibyshev, Acta Mater. 60 (2012) 487-497.

[24] C.W. Schmidt, C. Knieke, V. Maier, H.W. Höppel, W. Peukert, M. Göken, Scripta Mater. 64 (2011) 245-248.

[25] H. Akbari beni, M. Alizadeh, M. Ghaffari, R. Amini, Compos. B Eng. 58 (2014) $438-442$.

[26] Y. Liu, F. Wang, Y. Cao, J. Nie, H. Zhou, H. Yang, X. Liu, X. An, X. Liao, Y. Zhao, Y. Zhu, Scripta Mater. 162 (2019) 316-320.

[27] P.J. Apps, M. Berta, P.B. Prangnell, Acta Mater. 53 (2005) 499-511.

[28] J. Liu, Z. Chen, F. Zhang, G. Ji, S. Zhong, Y. Wu, M. Wang, G. Sun, H. Wang, Mater. Char. (2019) 155.

[29] Z. Chen, G.A. Sun, Y. Wu, M.H. Mathon, A. Borbely, D. Chen, G. Ji, M.L. Wang, S. Y. Zhong, H.W. Wang, Mater. Des. 116 (2017) 577-590.

[30] Z. Chen, J. Li, A. Borbely, G. Ji, S.Y. Zhong, Y. Wu, M.L. Wang, H.W. Wang, Mater. Des. 88 (2015) 999-1007.

[31] J. Liu, Z. Chen, F. Zhang, G. Ji, Y. Ma, M. Wang, S. Zhong, J. Li, H. Wang, H. Wang, J. Alloys Compd. 767 (2018) 293-301.

[32] J. Liu, Z. Chen, F. Zhang, G. Ji, M. Wang, Y. Ma, V. Ji, S. Zhong, Y. Wu, H. Wang, Materials Research Letters 6 (2018) 406-412.

[33] Y. Tang, Z. Chen, A. Borbély, G. Ji, S.Y. Zhong, D. Schryvers, V. Ji, H.W. Wang, Mater. Char. 102 (2015) 131-136.

[34] Y. Ma, A. Addad, G. Ji, M.-X. Zhang, W. Lefebvre, Z. Chen, V. Ji, Acta Mater. 185 (2020) 287-299.

[35] J.M. Dickson, T.H. Sanders, Mater. Char. 160 (2020) 110121.

[36] N. Su, R. Guan, X. Wang, Y. Wang, W. Jiang, H. Liu, J. Alloys Compd. 680 (2016) 283-290.

[37] O. Sitdikov, T. Sakai, H. Miura, C. Hama, Mater. Sci. Eng. 516 (2009) 180-188.

[38] I. Mazurina, T. Sakai, H. Miura, O. Sitdikov, R. Kaibyshev, Mater. Trans. 50(2009) $101-110$

[39] O. Sitdikov, T. Sakai, E. Avtokratova, R. Kaibyshev, K. Tsuzaki, Y. Watanabe, Acta Mater. 56 (2008) 821-834.

[40] S. Gao, C.S. Wu, G.K. Padhy, L. Shi, Mater. Des. 99 (2016) 135-144.

[41] K. Huang, R.E. Logé, Mater. Des. 111 (2016) 548-574.

[42] J.D. Robson, D.T. Henry, B. Davis, Acta Mater. 57 (2009) 2739-2747.

[43] F.J. Humphreys, M. Hatherly, in: Chapter 2 - the Deformed State, Recrystallization and Related Annealing Phenomena, second ed., Elsevier, Oxford, 2004, pp. 11-II.

[44] L. Burakovsky, C.W. Greeff, D.L. Preston, Phys. Rev. B 67 (2003).

[45] D. Tsivoulas, P.B. Prangnell, Acta Mater. 77 (2014) 1-16.

[46] F.J. Humphreys, M. Hatherly, in: Chapter 14 - Continuous Recrystallization during and after Large Strain Deformation, Recrystallization and Related Annealing Phenomena, second ed., Elsevier, Oxford, 2004, pp. 451-467. 
[47] Y. Liu, Y. Cao, Q. Mao, H. Zhou, Y. Zhao, W. Jiang, Y. Liu, J.T. Wang, Z. You, Y. Zhu, Acta Mater. 189 (2020) 129-144.

[48] J. Pešička, R. Kužel, A. Dronhofer, G. Eggeler, Acta Mater. 51 (2003) 4847-4862.

[49] F.J. Humphreys, M. Hatherly, in: Chapter 13 - Hot Deformation and Dynamic Restoration, Recrystallization and Related Annealing Phenomena, second ed., Elsevier, Oxford, 2004, pp. 415-V.
[50] F.J. Humphreys, M. Hatherly, in: Chapter 7 - Recrystallization of Single-phase Alloys, Recrystallization and Related Annealing Phenomena, second ed., Elsevier, Oxford, 2004, pp. 215-IV.

[51] P.J. Hurley, F.J. Humphreys, Acta Mater. 51 (2003) 3779-3793.

[52] J.D. Robson, D.T. Henry, B. Davis, Mater. Sci. Eng. 528 (2011) 4239-4247. 